\title{
HORIZONTES, NEGOCIACIONES Y DISYUNTIVAS EN LOS TRATOS DE YACIMIENTOS PETROLÍFEROS FISCALES BOLIVIANOS CON YACIMIENTOS PETROLÍFEROS FISCALES, 1937-1945
}

\author{
María Cecilia Zuleta \\ El Colegio de México, México \\ mczuleta@colmex.mx
}

\begin{abstract}
RESUMEN
Estas notas de investigación presentan un estudio de caso acerca de las distintas modalidades de vinculación establecidas entre dos compañías petrolíferas estatales de América del Sur, Yacimientos Petrolíferos Fiscales Bolivianos (YPFB) y Yacimientos Petrolíferos Fiscales (YPF), en unas décadas marcadas por problemas energéticos y dificultades en el terreno político y económico tanto interno como internacional de Bolivia y Argentina. Fundada a imagen y semejanza de YPF (la entidad argentina creada en 1922), empresa petrolífera estatal integrada verticalmente, la YPFB (entidad boliviana creada en 1936) desarrolló desde sus orígenes diversas estrategias para vincularse en el terreno técnico, de la producción, transporte y distribución de combustibles, con los YPF argentinos. El texto examina y proporciona elementos informativos puntuales acerca de las conexiones, los tratos, acuerdos y negociaciones, su dinámica, instrumentos y prioridades, explicando su contexto y razones. Se examina la trama de negociaciones entre ambas compañías petroleras estatales, con el propósito de esclarecer un antecedente temprano de las más recientes experiencias de interacción internacional de empresas estatales en el marco de procesos de integración energética regional amplia. Se propone que la interacción entre las dos YPF fue efímera, debido a que su agenda fue superada por las ventajosas posibilidades ofrecidas por la cooperación, en el marco de programas hemisféricos, por las agencias de gobierno de los Estados Unidos.
\end{abstract}

Palabras clave: Empresas públicas, Empresas petroleras nacionales, Cooperación internacional, Argentina, Bolivia. 


\title{
PERSPECTIVES, NEGOTIATIONS AND DILEMMAS \\ IN THE TRANSACTIONS BETWEEN YACIMIENTOS \\ PETROLÍFEROS FISCALES BOLIVIANOS (YPFB) AND \\ YACIMIENTOS PETROLÍFEROS FISCALES (YPF), \\ 1937-1945
}

\begin{abstract}
These research notes present a study about the linkages established between two state oil companies in South America, YPFB and YPF, in a few decades marked by economic, energy and political problems in Bolivia and Argentina. Founded in the image and likeness of YPF (Argentina entity created in 1922), state oil company vertically integrated, the YPFB (Bolivian entity created in 1936) developed from its origins several strategies to link in the technical, production, transportation and distribution of fuel, with the Argentinian YPF. The article provides specific information elements about connections, dealings, agreements and negotiations, dynamics, instruments and priorities, explaining its context and reasons. Moreover, this text explores the plot of negotiations between state oil companies, in order to clarify an earlier history of the most recent experiences of international interaction of state companies in the frame of energetical integration processes. It is proposed that the interaction between the two YPFs was ephemeral, because their agenda was overtaken by the favourable opportunities offered by cooperation within the framework of hemispheric programs, by agencies of the U.S. government.
\end{abstract}

Keywords: Public companies, National oil companies, International Cooperation, Argentina, Bolivia. 


\section{INTRODUCCIÓN}

La historia de las compañías petroleras estatales inició en Latinoamérica con la fundación de Yacimientos Petrolíferos Fiscales en Argentina en 1922, siendo ésta la primera petrolera estatal que integró las funciones de exploración, explotación, producción, industrialización, comercialización y distribución de hidrocarburos del continente (Gadano 2006:146). Hoy, casi un siglo después, mediando cambios $-\mathrm{y}$ vaivenes- en su marco jurídico regulatorio, así como transformaciones profundas en su estructura financiera, organizativa y operativa, aún subsisten algunas de las empresas petrolíferas estatales fundadas en la primera mitad del siglo XX en la región (al lado de otras fundadas con posterioridad a la Segunda Guerra Mundial como Petróleo Brasileiro (Petrobras, 1953) o Petróleos de Venezuela S.A., (PDVSA), 1975), que explotan, industrializan y comercializan energéticos ${ }^{1}$.

El propósito de este artículo es estudiar un temprano episodio de vinculación internacional entre dos históricas empresas petroleras estatales, YPFB (Yacimientos Petrolíferos Fiscales Bolivianos), fundada en 1937, e YPF (Yacimientos Petrolíferos Fiscales de Argentina), fundada en $1922^{2}$. Esta vinculación podría considerarse como un antecedente lejano de los procesos de constitución de comunidades energéticas que se fincaron en tiempos recientes en Latinoamérica, con posterioridad a la creación de las organizaciones multilaterales, como la Asociación Latinoamericana de Libre Comercio (ALALC, 1960) y la Organización Latinoamericana de Energía (OLADE, 1973) ${ }^{3}$. Para ello, examinamos la interacción que desarrollaron estas entidades petroleras estatales -YPFB e YPF- en un lapso temporal corto, la breve coyuntura de negociación de acuerdos bilaterales entre los gobiernos argentinos y bolivianos con el fin de lograr una integración ferroviaria, comercial y petrolera entre 1937 y 1945 . Este periodo posterior a la Guerra del Chaco y hasta el fin de la Segunda Guerra Mundial fue de gran inestabilidad política en Bolivia, con predomino de

I Para I990, momento clave de liberalización sectorial, las principales empresas petroleras estatales de Latinoamérica eran: PDVSA (Venezuela), Petróleos Mexicanos, Pemex (México), Petrobras (Brasil), YPF (Argentina), Empresa Colombiana de Petróleo, Ecopetrol (Colombia), Petróleos del Ecuador, Petroecuador (Ecuador), Empresa Nacional del Petróleo, ENAP (Chile), Petróleos del Perú, Petroperú (Perú), Administración Nacional de Combustibles, Alcohol y Portland, ANCAP (Uruguay) y YPFB (Bolivia).

2 En I994 las ventas de YPF significaron un aproximado de 2,4\% del PIB de Argentina, y las de YPFB un 9,5\% del PIB de Bolivia (Vargas Salgueiro I 996: 252).

3 Estos procesos de integración fueron vertebrados y configurados mediante negociaciones de diplomacia comercial y empresarial de carácter multilateral en la segunda mitad del siglo XX y primera década del actual. ALALC fue fundada sobre la base del Acuerdo de Montevideo, i 8 de febrero de I960, OLADE en I973. En este último organismo, convergieron las empresas públicas de Latinoamérica productoras y suministradoras de energía en la región (Bertoni y Travieso 20 I 2: 6-8). 
gobiernos militares de corte nacionalista, y en Argentina se sucedieron varios presidentes y un golpe militar, que sería luego continuado por la primera presidencia de Juan Domingo Perón (1946-1952). El contexto económico internacional, regional y hemisférico que enfrentaron ambas naciones fue muy complejo (Rapoport 2005: 214-238, 280-296, Zanata 2005, Figallo 1996).

En este sentido, el propósito puntual de este estudio es brindar evidencia empírica que arroje luz sobre las relaciones que se establecieron entre estas dos empresas petroleras estatales durante 1937 y 1945, de cara a una incipiente vinculación comercial y petrolera binacional. Si bien estos tratos fueron limitados y efímeros, su proyección de largo alcance-aunque originalmente no fue previsto así- puede observarse actualmente en la red de oleoductos, gasoductos y poliductos que surcan la región transfronteriza entre el noroeste de la República Argentina y la zona media y sur oriental de Bolivia. De este modo, el caso de estudio puede considerarse como un lejano antecedente de los proyectos y construcción de redes energéticas por corredores internacionales que surcan el sur del continente americano, vinculando el eje Andino a los países del Mercado Común del Sur (Mercosur) y asociados (Rousseau 2006, Carrizo Rasmousse 2010: 55, Ceppi 2010: 9).

El perímetro de este trabajo es circunscrito a un caso de estudio y sus términos disciplinarios la historia internacional, antes que la historia económica de empresas. En lugar de estudiar desde una perspectiva histórica la constitución y funcionamiento de estas dos empresas estatales (su marco regulatorio, entramado institucional y constitución financiera, evolución, estrategia y desarrollo, estructura burocrática, organización administrativa, gerencial, técnica y funcional, relación con los actores públicos y actores privados), nos enfocamos aquí en una dimensión precisa de su operación: la vinculación internacional. Nos interesa aquí examinar la dinámica de negociaciones diplomáticas y técnico-petroleras que se suscitaron en torno a la posibilidad de producción, transportación y comercialización internacional de petróleo boliviano desde la región sub andina a la platense. Ambas compañías estatales acometieron la vinculación energética internacional entre las regiones sur andina y platense, con una prioridad puntual: el fortalecimiento y protección de la industria y mercados internos domésticos (Garibay 2006: 26). Esta finalidad en la búsqueda de conexiones energéticas difiere de los objetivos que alientan los procesos de integración energética contemporáneos, más bien orientados a la complementación energética en un espacio económico global. En suma, esta investigación supone un desplazamiento analítico del estudio histórico de la empresa y de la empresa pública, al campo del estudio 
histórico de las relaciones internacionales, y en particular, de los procesos de complementación e integración energética y comercial vistos en la larga duración.

Nuestro objetivo es examinar la dinámica y los mecanismos de negociación entre YPFB e YPF durante la discusión del primer acuerdo bilateral de construcción de conexiones físicas para el transporte de combustibles entre Argentina y Bolivia, concluido por los gobiernos de ambos países en 1941, posteriormente convenido e instrumentado por YPF e YPFB en el curso de 1942 y renegociado en 1945. Teniendo en cuenta que estos acuerdos discutidos por los técnicos de YPFB con YPF, autoridades y agencias de gobierno argentinas, superaban el simple comercio de energéticos, y buscaban establecer medidas en beneficio de a ambas economías como parte del intercambio de combustibles y otros bienes (como la infraestructura de comunicación ferroviaria), consideramos que pueden ser un antecedente de los procesos de integración regional.

La literatura histórica especializada sobre energéticos señala que hubo tempranos nexos entre ambas empresas desde el momento de consolidación de YPF y de fundación de YPFB, que se reflejaron en la arquitectura empresarial de la compañía boliviana y en conexiones institucionales y técnicas de ésta con YPF. Se ha señalado que estas conexiones fueron efímeras, que obedecieron en realidad a proyectos políticos y económicos específicos y que cambiaron rápidamente en sincronía con las transformaciones económicas y del contexto político que fueron aconteciendo. Sin embargo, aún no se conoce mucho sobre estos vínculos, y se requerirían nuevas investigaciones. Al respecto, cabe señalar que el responsable de la privatización de YPF e impulsor de la desregulación del sector petrolífero argentino en décadas posteriores fue el destacado ingeniero petrolero boliviano José Estenssoro. Ello sugiere la conveniencia de formular, a futuro, estudios que emprendan una reflexión detenida de los ciclos de vida de estas dos empresas petroleras estatales, vinculadas por una larga historia de encuentros, desencuentros, tratos y negociaciones muy diversas en un espacio energético compartido, que no han sido exploradas lo suficiente.

En estas notas buscamos esclarecer tres aspectos de la vinculación de YPFB con YPF en el corto periodo de la post guerra del Chaco: 1) la dinámica negociadora, una línea de tiempo; 2) la agenda de negociación; 3) los actores participantes; 4) las prioridades de ambas empresas en la negociación, y 5) los mecanismos e instrumentos que se activaron en las negociaciones. Si bien en este estudio histórico se aportan principalmente elementos informativos, consideramos que ellos podrían ser de utilidad para una futura reflexión y conceptualización teórica sobre los diferentes 
tipos de procesos de internacionalización y complementación que las petroleras estatales latinoamericanas han gestado a lo largo del siglo XX. Algunos de estos procesos han estado enraizados principalmente en las necesidades del mercado interno y otros muy posteriores, en las vicisitudes planteadas por las dinámicas de la internacionalización, globalización y complementariedad energética (Bertoni y Travieso 2012).

Los datos, tendencias y la dinámica general del comercio bilateral argentino-boliviano en el periodo de estudio no se analizan aquí detenidamente. En particular, el comercio y complementación de combustibles entre estas naciones merece la atención de una investigación sistemática. Por ahora, tomamos como base una estimación presentada por el servicio comercial exterior británico, que calcula para el lapso de 19391943 un incremento de las importaciones argentinas de Bolivia (valores), pasando éstas del 13,9\% del total importado en 1939 a 35,5\% en 1943 (Bolivia 1944: 20) ${ }^{4}$. Los otros socios comerciales principales de Bolivia en la región eran Perú y Chile, y en el continente los Estados Unidos, mientras en Europa Gran Bretaña, Alemania, Francia y Bélgica. Entre 1937 y 1945, Bolivia firmó convenios de comercio, cooperación ferroviaria y caminera, así como petrolíferos, con Brasil y Argentina. Asimismo, suscribió convenios y tratados de comercio y cooperación intelectual con Chile y Perú, y llevó negociaciones de comercio con Uruguay en el mismo periodo, y con Paraguay entre 1938 y 1939 (Ostria Gutiérrez 1946). Pero, un estudio que examinara las relaciones YPF-YPFB vistas como parte de negociaciones generales de comercio bilateral boliviano-argentino, es algo que no emprendemos aquí, aunque sería sin duda otra manera de aproximarse al problema de las interacciones entre las industrias petroleras de la región sudamericana ${ }^{5}$.

Las fuentes empleadas en esta investigación son diversas, pero imprimen un sesgo analítico y posiblemente interpretativo: son principalmente documentos de procedencia diplomática. Se consultaron también los informes de YPFB, en particular los reportes de su representante oficial

4 La misma fuente marca a los Estados Unidos como proveedores en I 939 del $25 \%$ del total de las importaciones bolivianas, y en I 943 del $32 \%$ de éstas. Las exportaciones bolivianas al mercado argentino no parecen haberse incrementaron notablemente entre 1939 y 1942, más que en medio punto, sin embargo, requerimos formar una base de datos del comercio bilateral para el periodo I920-I953, hasta el primer gobierno del revolucionario Movimiento Nacionalista Revolucionario, por lo menos, para obtener una apreciación exacta de las tendencias y los cambios en este comercio.

5 En este sentido, cabe señalar que el arranque de los tratos y negociaciones YPFB-YPF en I937, tuvo lugar en el marco de un descenso de los precios internacionales del estaño, la principal exportación de Bolivia. La Segunda Guerra Mundial alteró de forma sustantiva el régimen mundial del comercio de estańo, particularmente desde de 1942 (Campero I999). 
en las oficinas de Buenos Aires acerca de las negociaciones de los acuerdos entre ambas compañías, los informes de su Directorio y el informe de la Misión Económica Estadounidense de 1941, encabezada por Merwin Bohan, experto ingeniero con larga trayectoria en el negocio petrolero ${ }^{6}$. Del lado argentino, junto a documentación diplomática ${ }^{7}$, se emplearon las memorias e informes publicados en el Boletín de la Dirección General de YPF. Ello posibilita una aproximación a la perspectiva estratégica y enfoques operacionales de la empresa argentina y a sus interacciones con la estatal boliviana.

\section{LAS ASIMETRÍAS DE DOS EMPRESAS PETROLERAS ESTATALES Y SUS HORIZONTES PRODUCTIVOS}

Durante la segunda mitad de la década de 1920, se consolidó un ciclo de expansión de la inversión extranjera directa en la actividad petrolera en América del Sur, particularmente en la exploración, producción e industrialización del petróleo y en la comercialización de combustibles, proceso retroalimentado además por la transición energética en la región del consumo de combustibles sólidos a los hidrocarburos (Wilkins 1974, Rubio et al. 2010).

En este contexto, el Ejecutivo argentino creó el ente estatal Yacimientos Petrolíferos Fiscales, en 1922, como una dependencia del Ministerio de Agricultura y de su Dirección de Minas, Geología e Hidrología, para explotar e industrializar el petróleo de las reservas fiscales que el propio Ministerio de Agricultura fijaba en el territorio nacional (Favaro 1987) ${ }^{8}$. YPF siempre coexistió con las compañías petroleras privadas, grandes y pequeñas, pero en continuo conflicto. Era una institución única en su tipo en la región, pues además de prefigurar al Estado Empresario que

6 Esta documentación se encuentra en los archivos diplomáticos bolivianos. En adelante, Archivo Histórico de la Cancillería de Bolivia, AHCB, Yacimientos Petrolíferos Fiscales, I937-I945, varios volúmenes; Bohan (1942).

7 En adelante Archivo Histórico de la Cancillería, Argentina, en adelante ACA, división política, Bolivia.

8 No nos referimos aquí al debate interdisciplinario largo y extendido, en torno a la conceptualización de YPF argentina como empresa estatal o empresa pública, ente estatal o ente autárquico. Una postura general y amplia coincide en considerarla empresa estatal en la medida en que era entre 1930 y 1940 un organismo de propiedad estatal, capital estatal y responsabilidad de la gestión estatal, dirigido por funcionarios nombrados por el Poder Ejecutivo y controlado por otros organismos del Estado (Ministerio de Agricultura principalmente, pero también el Ministerio de Economía y luego, posteriormente, la Dirección Nacional de Energía, en 1943), con libertad para disponer de los recursos que generara su actividad, más aportes del Tesoro Nacional, con autonomía de empleo de tecnología, de recursos y de planificación, pero sin facultad de decisión en materia de gran obra pública o materia internacional. 
se configuró en Argentina algo más de una década después (Belini y Rougier 2008), se proponía el establecimiento a manos del Estado de una industria petrolera verticalmente integrada. En dos décadas, alimentada por la dinámica económica agrícola e industrial del país, y con base en la inversión estatal del gobierno nacional y mediante la administración de los rendimientos obtenidos por las ventas de combustibles, YPF consiguió despegar en un ciclo expansivo -no exento de dificultades-, y erigir una industria petrolera estatal con capacidad de producción suficiente para abastecer una parte considerable de la demanda nacional de hidrocarburos.

El robustecimiento empresarial y productivo de YPF aconteció precisamente en la segunda mitad de la década del treinta, cuando logró abastecer con su producción más del $41 \%$ del consumo nacional de hidrocarburos (al lado del 30\% en 1930). En contraste, por entonces la recién creada YPFB apenas alcanzaba a colocar sólo algo más del 20\% del consumo total de hidrocarburos de Bolivia, y mantenía tres pozos en producción. En 1940, la empresa producía muy poco en los estándares internacionales, apenas 213.000 barriles al ańo'. Del otro lado, para 1941 la empresa argentina tenía en explotación unos sesenta pozos, producía $1.672 .000 \mathrm{~m}^{3}$ de combustibles líquidos, disponía de una flota fluvial y marítima propia con capacidad de bodega de más de 81.000 toneladas y controlaba, en permanente pugna con otros intereses empresariales privados, una red de expendedoras de gasolina de más de seiscientos surtidores (BYPF 1941[febrero]: 61-92).

El afianzamiento técnico, productivo, financiero y comercial con el que la Segunda Guerra Mundial encontró a YPF en 1939 habría sido resultado más que de una gerencia exitosa, del impulso protector de las políticas de gobierno, en particular las presidencias de Agustín P. Justo (1932-1938) y subsiguientes (R. M. Ortiz, 1938), que buscaban una salida a la crisis de las exportaciones tradicionales, apostando a la industrialización, al mercado interno y a la formación de bloques regionales, como se puede observar en ejemplos concretos como el Plan Pinedo (Gadano 2006, Cramer 1998). Es de notar lo tardío de la Ley orgánica de la empresa, que fue aprobada el 13 de diciembre de 1932 (YPF 1932: 427-429). Ésta otorgó a YPF autonomía relativa para administrar su presupuesto, aunque en lo concerniente a inversiones y adquisiciones para grandes obras quedó dependiente de la aprobación del Ejecutivo. La Ley de Petróleos, que durante una década completa estuvo apresada en los vericuetos de numerosos proyectos y dilaciones del Congreso y las negociaciones con las provincias petroleras,

9 En contraste, en 1939 Venezuela producía 205.956 miles de barriles, Colombia 22.037, Argentina I8.486, Perú I3.508 y Ecuador 2.313 (United States Tariff Commission I942 I: I 58, Royuela Comboni I 996: 226). 
fue sancionada apenas en $1935^{10}$, cuando YPF consiguió imponer su producción de refinados en el mercado interno argentino, así como fijar las cuotas de importación de combustibles para todo este mercado, y exportar pequeños cargamentos de destilados a los países vecinos (principalmente Paraguay y Uruguay e incluso a Brasil) (United States Tariff Commission 1942 III).

Ahora bien, el estado actual del conocimiento histórico acerca del pasado de las empresas YPF e YPFB es tan asimétrico como lo eran ambas organizaciones en el año de 1940. Una YPF consolidada en términos técnicos y operativos, que desplegaba una estrategia de expansión de la investigación y exploración (reconocimiento reservas y nuevos yacimientos), de la producción, de los negocios del transporte y distribución, que abastecía cerca del y que empleaba un total de 18.403 trabajadores (YPF 1943: 89), contrastaba entonces con una YPFB apenas incipiente, limitada en recursos financieros y técnicos y restringida en cuando a su organización administrativa, capacidad productiva y mercados (Mariaca 1944). En un paralelo sólo justificable en términos expositivos, esa asimetría entre ambas empresas a lo largo de la Segunda Guerra Mundial encuentra réplica en la literatura especializada, expresada en que mientras la evolución de YPF ha recibido desde hace unos años una atención sobresaliente particularmente el notable estudio de Nicolás Gadano (Gadano 2006)-, los estudios históricos sobre los comienzos y primeras etapas de YPFB no son numerosos, y sólo para el periodo posterior a 1952 son más abundantes. Por ello, teniendo en cuenta esta limitación, en este trabajo nos detenemos más en la estatal boliviana, fundada en diciembre de 1936, para luego concentrarnos en las interacciones entre ambas empresas.

La empresa estatal YPFB, fundada a fines de 1936 cuando apenas culminaban las negociaciones de la paz del Chaco (Rout 1970, Klein 1981, Hernández 2013), fue convertida en marzo de 1937 en una empresa autárquica después de una estruendosa incautación de la compañía estadounidense Standard Oil de Bolivia ${ }^{11}$. El capital original con que se dotó a la empresa es materia de divergencia en las fuentes consultadas. Para unos autores la suma fue de 100.000 bolivianos, luego ampliado a 30.000.000, aproximadamente unos US\$ 700.000; llama la atención lo

Io Ley N. ${ }^{\circ}$ I 2.I6I, sobre régimen legal de minas de petróleo e hidrocarburos fluidos, I935 (República Argentina).

I I Esta sección reproduce en gran medida los argumentos de Zuleta (20II). Desafortunadamente, el estado actual de nuestra investigación no permite construir un estudio histórico de la empresa YPFB comprensivo y documentado. La documentación examinada hasta la fecha presenta discontinuidades y discrepancias, inclusive en los volúmenes empastados de la propia empresa YPFB consultados en el Archivo Histórico del Ministerio de Relaciones (Bolivia), para los ańos I 937 a I 943. 
bajo de cifra atendiendo a los altos requerimientos de la industria y su entrega incompleta a la empresa (Almaraz 1958: 187). Algunas fuentes señalan que se intentó tramitar un crédito con la Corporación Industrial Comercial Argentina por $£ 500.000$, gestión luego abortada, por presuntos antagonismos políticos entre los círculos allegados a los gobiernos de D. Toro y G. Busch y por causa de los dilemas y vaivenes geopolíticos de las cancillerías boliviana y argentina cuando se negociaba la paz de la guerra del $\mathrm{Chaco}^{12}$. En el presupuesto extraordinario del Ejecutivo nacional boliviano ejercido el año 1937-1938, se puede observar que solamente se habían pagado una parte de las acciones del Estado a YPFB ${ }^{13}$, aunque pocos después de su creación la empresa recibió los bienes incautados a la Standard Oil para su administración y gestión. En mayo del mismo año 1937 se dictó su Ley orgánica. Esta ley otorgaba a la estatal petrolera boliviana la gestión de "los intereses del Estado relacionados con el petróleo y demás hidrocarburos" en dependencia del Ministerio de Minas y Petróleo (por lo menos hasta 1942, luego esto se modificó). En este sentido, la YPFB fue definida como "entidad fiscal, industrial y comercial encargada de organizar y dirigir la explotación, comercialización, industrialización y transporte de los hidrocarburos y sus derivados", y "organismo asesor en todos los actos, sin excepción, que se refieran al petróleo" (artículo 2). La ley dotaba a la empresa de personería jurídica, y reconocía como inalienables e imprescriptibles los yacimientos que le habían sido asignados, asimismo, declaraba autónoma a la entidad y disponía su administración a un directorio de un presidente y cuatro vocales (elegidos por cada diez años), finalmente otorgaba a YPFB independencia presupuestaria respecto al erario de la nación (artículos 4 y 10) ${ }^{14}$.

Si el conjunto de estas disposiciones fijaba las funciones de la empresa, quedaron en la nebulosa sus competencias fiscales y régimen financiero. A partir de las fuentes localizadas no es posible descifrar la organización

I 2 AHCA, Bolivia (División Política), I936, exp. 9, Horacio Carrillo a Carlos Saavedra Lamas, 26 de marzo I938, muy reservado. La posición de los intereses argentinos era complicada puesto que el canciller argentino Carlos Saavedra Lamas encabezaba una muy controversial gestión de las negociaciones de Paz, imponiendo ello vaivenes y fuertes altibajos a la dinámica de las relaciones comerciales y financieras de Bolivia con Argentina, Paraguay, Brasil, Chile y Perú, Holland (I967); Rout (I970).

I3 Aún con el incremento de fondos determinado a YPFB en I938, estos fueron inferiores a los compromisos pendientes en gasto de defensa e indemnizaciones de guerra para ese año. Los fondos asignados al recién creado Ministerio de Minas y Petróleo fueron incluso inferiores a Agricultura y Colonización, y tampoco fueron pagados en su totalidad (Superintendencia de Bancos I938: I7). Esta asimetría es indicadora del nivel de prioridades que ocuparon los asuntos petroleros para los gobiernos de Toro y Busch.

I 4 La misión estadounidense encabezada por M. Bohan propondría reformas a la conformación del directorio en I94I. 
burocrática, técnica y funcional de YPFB, ni tampoco dibujar su organigrama administrativo y funcional. Queda la impresión de una estructura desorganizada, débil y dependiente de las personalidades y sus redes personales, empresariales y políticas privadas ${ }^{15}$. Las gestiones inmediatas realizadas por YPFB fueron el alquiler de una casa para la instalación de las oficinas de la empresa, el inicio de la construcción del edificio sede y el establecimiento de una oficina de la entidad junto a las oficinas de la Legación de Bolivia en Buenos Aires, centro de los negocios petrolíferos de la zona del Plata ${ }^{16}$. Esta oficina fue fundamental en la estrategia financiera y de mercado de YPFB en el periodo que estudiamos, como se verá más adelante.

Si bien la YPFB no tuvo en origen la exclusividad de la explotación ni de la distribución y comercialización de combustibles por su Ley orgánica, muy pronto, al eliminarse a la Standard Oil, el principal operador de los negocios petroleros, quedó de facto sin competencia y con un virtual monopolio en el transcurso de su primer año de operaciones. Posteriormente, serían reguladas sus funciones en la distribución de combustibles, en particular, la importación y distribución de gasolina y kerosene, y ello constituiría un asunto de polémica pública en la prensa. En contraste, la empresa argentina YPF había enfrentado por décadas dificultades en el mercado de naftas: abastecía a un segmento del mercado argentino, y mantenía una lucha sin cuartel con sus competidoras multinacionales Shell Mex y Standard. Pero, en 1936 YPF consiguió un acuerdo de coexistencia con éstas gracias a la intervención del Ejecutivo nacional: la estatal petrolera argentina logró entre 1936 y 1937 (con unos convenios por cuatro ańos hasta 1940) casi un rol exclusivo en el segmento de la exploración y producción, un 30\% del mercado interno, y la exclusividad en la determinación del quantum de las importaciones de hidrocarburos, así como la exclusividad en la importación de crudo, todo lo cual significaba el control del mercado y la subordinación de las petroleras extranjeras. En 1940, la empresa tenía el $48 \%$ del mercado de naftas a expensas de las compañías privadas y extranjeras (Gadano 2006: 356-404).

I 5 A la vez, la relación de YPFB con el Ministerio de Minas y Petróleo (Ministerio del cual dependía según su Ley orgánica hasta I942) aparece en las fuentes como fluctuante y complicada, puesto que el primer Director de YPFB, Dionisio Foianini, fungió como Ministro de Minas y Petróleos del gobierno del comandante Germán Busch.

I6 Durante la gestión de Foianini, la oficina en Buenos Aires quedó a cargo del alemán Walter Mohring, quien estuvo encargado de negociar un convenio con el Reich (petróleo por maquinaria y fondos del Banco). Estas negociaciones atrajeron el recelo de la diplomacia estadounidense y también la atención de la prensa argentina y chilena. 
Al contrario que el argentino, el mercado boliviano no era un negocio muy rentable para las compañías extranjeras, dada su reducida escala y la incertidumbre en los derechos de propiedad, debido a que el juicio de amparo presentado por la Standard ante la Corte Suprema de Justicia se mantenía en proceso (finalizó en marzo de 1939) ${ }^{17}$. Sin un financiamiento gubernamental claramente especificado YPFB quedaba librada a su suerte, y ello explica en buena medida, la estrategia financiera que desplegó sin mucho orden entre 1937 y 1939 inclusive. El país aún no había finalizado la negociación de paz con El Chaco, se encontraba aplastado por los costes de guerra y la caída de los precios del estaño y no tenía posibilidades de aspirar a crédito internacional debido a la moratoria de deuda externa de 1931 y al conflicto con la Standard. Al lado de esta situación, el estallido de la Segunda Guerra Mundial impuso severas limitaciones en la dinámica comercial mundial y sudamericana, coartando aún más las posibilidades de financiamiento y asfixiando, por la dificultad de adquisición de bienes de capital y maquinaria de perforación, aún más las funciones de producción y distribución de combustibles de YPFB. A pesar de lo anterior, el conflicto bélico internacional también vendría acompañado de oportunidades en la comercialización de minerales sólidos e hidrocarburos.

YPFB quedó a cargo de todas las instalaciones de la Standard desde abril de 1937, y responsable de la exploración de la zona de reserva de terrenos petrolíferos fiscales y de la explotación de hidrocarburos en el territorio nacional (sola o conjuntamente en sociedad con otras compañías). Fue dotada del privilegio de la proveeduría a todas las dependencias de gobierno, a lo que se agregó la importación, transporte, distribución y venta de combustibles de procedencia foránea o local ${ }^{18}$. En octubre de 1937, la estatal boliviana adquirió, por decreto del Ejecutivo nacional, el activo y el pasivo de la Compañía Nacional Distribuidora de Petróleos, una empresa mixta con participación de acciones del Estado y particulares,

I7 En diciembre de 1936 se había ordenado que todo juicio sobre procesos mineros instaurado con anterioridad a septiembre de 1936 quedaba circunscrito a los tribunales ordinarios de justicia, AHCB, Minas y Petróleo, junio I936-diciembre 1937. La incautación de la Standard se dispuso en marzo de 1937 con motivo de incumplimiento fiscal y fraude de esta empresa, que en respuesta gestionó un juicio de Amparo contra YPFB y el Estado boliviano. Una vez desahuciada la empresa, las negociaciones con la Standard se prolongaron, con interrupciones, hasta I94I, cuando en medio de la Segunda Guerra Mundial los gobiernos bolivianos resolvieron pagar una indemnización a la Standard (que se aplicó en 1942) para destrabar así las ayudas económicas y los acuerdos del estaño con los Estados Unidos, AHCB, Standard Oil Minas y petróleo, y Desahucio de la Standard Oil of Bolivia, I937I94I, varios volúmenes.

I8 En septiembre de 1937 un decreto reguló el aprovisionamiento gubernamental. Otro decreto prohibió a YPFB otorgar préstamos de financiamiento a oficinas y reparticiones públicas, así como también la Defensa. AHCB, Ministerio de Minas y Petróleos, junio I936-diciembre I937. 
que tenía contratado con el Gobierno y con la Standard Oil la distribución de combustibles ${ }^{19}$. Casi un año después, YPFB quedó responsabilizada de aportar regalías al tesoro nacional, descontados los porcentajes correspondientes a las regalías de los departamentos productores (Mariaca 1966: 380-382). Y había logrado que los ferrocarriles tuvieran dotación y disponibilidad de vagones tanque para transportar combustible hacia los centros consumidores, además de la Paz, Sucre y Cochabamba, Oruro y los principales centros mineros (Royuela Comboni 1996: 83).

La administración y funcionamiento operativo de YPFB fue puesta en cuestionamiento en el debate político por diferentes grupos reiteradamente (principalmente, el manejo financiero, las decisiones acerca de la exploración y perforación, y las resoluciones sobre las modalidades de vinculación internacional de la empresa). La toma de decisiones arbitrarias sobre la empresa sin el debido criterio técnico por parte del Ejecutivo y sus ministros (por ejemplo, el Ministerio de Relaciones Exteriores) mereció varias interpelaciones del legislativo (por ejemplo, en marzo-abril de 1941, cuando se discutieron los proyectos de indemnización a la Standard y los acuerdos de vinculación ferroviaria y petrolífera con Argentina) (La Calle 1941, Comité Pro Defensa de los Intereses Cruceños 1942).

Para atender las necesidades de comercialización del crudo que se obtuviera en los pozos del país que se intentaba recuperar intensificando la explotación, el Ministerio de Relaciones Exteriores de Bolivia suscribió, mediando las gestiones del Presidente de YPFB, Dionisio Foianini, un primer acuerdo preliminar de vinculación ferroviaria y tráfico de petróleo con Argentina en noviembre de 1937, que fijó ventajas arancelarias exclusivas para el crudo boliviano que produjera la empresa estatal YPFB. Y para atender a las necesidades de exploración, la misma que había sido abandonada hacía tiempo por la Standard Oil de Bolivia, la Cancillería y la Dirección de YPFB gestionaron una negociación con el Gobierno de Brasil, que produjo como resultado la firma de convenios ferroviariopetroleros con este país a comienzos de 1938. Estos convenios estipulaban la constitución de una zona de exploraciones geológicas y petrolíferas conjunta en la región que atravesaría la vía férrea proyectada. Así se establecieron zonas petrolíferas fiscales, que se definirían con más precisión una vez determinada una comisión mixta boliviano-brasileña en el oriente del país. Éstas quedaron establecidas como muestra el Cuadro 1:

I9 El funcionamiento del mercado de combustibles boliviano (más allá de su volumen relativo reducido, en contraste con el de otros países de la región) no es conocido, debido a la escasez de estudios específicos. Los estudios de Jacob (I 979), Bertoni (2006), Malgesini y Álvarez (1982), y Gadano (2006) iluminan el funcionamiento de los mercados de hidrocarburos en Uruguay y Argentina respectivamente. Para el conjunto de Latinoamérica antes de I930 véase Rubio et al. (2010). 


\section{Cuadro 1: Diferenciación de zonas para explotación petrolíferas en Bolivia, según marco legal, 1937-1945}

\author{
Desarrollo petrolífero \\ exclusivo de YPFB
}

YPFB conjuntamente con sociedades mixtas

Zona reserva Comisión Mixta Boliviano-Brasileńa para explotación conjunta capitales ambos países
1. Zona Sub Andina Pedemontana (entre frontera argentina y paraguaya)

2. Zona Valles Cochabamba

3. Zona Altiplánica

Todo el resto del territorio nacional

Parte Noroeste Zona Sub Andina con límites Río Parapeti y Río Ichilo

Fuente: Zuleta (2011). Elaboración propia con base en AHCB. Informe del Ingeniero Jorge Lavadenz, Presidente YPFB, al Ministro de Relaciones

Exteriores, 30 de junio de 1945. AHCB, Yacimiento Petrolifero Fiscal Boliviano, 1939-1945.

En el Cuadro 1 es posible observar que la zonificación dispuesta por los convenios con Brasil no carecía de ambigüedad y potencial para el litigio y la impugnación de posibles interesados. Entre 1937 y 1945 las operaciones de YPF se concentraron en su zona de exclusividad y en menor medida dentro de la zona de la Comisión Mixta (puesto que ese petróleo de comenzar a explotarse no contaba con vías de salida). La actividad se desplegó particularmente en la zona 1, en tres puntos principales: Sanadita, Camiri y Bermejo. Este último se encontraba en abandono, por lo cual requirió un plan completo de reactivación y explotación que fue discutido tanto con YPF argentinos como con la misión técnica estadounidense (véase Cuadro 2). Simultáneamente, se planeó la construcción de refinerías modernas en esos tres centros, para lo que se requería de crédito internacional y maquinaria especializada, temas que se convirtieron en materia de gestión ante los países vecinos y Alemania entre 1937 y 1941 (Zuleta 2011) ${ }^{20}$.

La salida natural geográficamente determinada de los hidrocarburos que se produjeran en la zona 1 era la región platense, ya fuese por vía fluvial, ferroviaria, o por oleoductos, a pesar de que todas estas conexiones estaban por construirse. La salida al pacífico estaba complicada por la orografía, y también por un asunto de costos: el Perú producía y exportaba en el Pacífico

20 El Cuadro 2 se encuentra anexo al final del texto por razones de espacio. 
crudo más barato que el boliviano, y refinados. Así que la salida del crudo boliviano estaba impuesta por la naturaleza: el Brasil o El Plata. La orografía llevaba al extremo las paradojas del competido recurso petrolífero del Chaco boliviano: era más sencillo sacar el crudo por la frontera del Noreste argentino y reintroducirlo por vía ferroviaria hacia los centros de consumo principales (La Paz, Sucre, Cochabamba), que transportarlo directamente. O en su defecto, era más sencillo importar -y más barato- todo tipo de hidrocarburos desde Perú. Ello explica la estrategia de la joven empresa YPFB y de su gerencia (aún a pesar de los cambios en sus cuadros gerenciales), de apostar el desarrollo de conexiones internacionales que posibilitaran la superación de los problemas de explotación, industrialización, transporte y comercialización de los petróleos bolivianos.

La Standard no había logrado abastecer el mercado con su propia producción, además, tenían en sus dos campos de Camiri y Sanandita una mayor cantidad de pozos abandonados que en producción y dos pequeñas refinerías medio desmanteladas ${ }^{21}$, a pesar de que dichos campos eran los únicos en operación y con posibilidad de salida de sus productos por contar con vías de comunicación a los centros de consumo. YPFB requería incrementar urgentemente la producción, y potenciarla de forma tal de conseguir el autoabastecimiento del mercado interno, hasta entonces estancado de no ser por el impulso extraordinario de la guerra con el Paraguay. Necesitaba importar hidrocarburos refinados, para completar la demanda local, dado que la capacidad instalada de las pequeñas refinerías incautadas era reducida.

Las necesidades de la petrolera estatal boliviana eran difíciles de solventar debido a severas limitaciones como falta de capitales, de información geológica $^{22}$, de tecnología y maquinaria especial para la prospección, perforación y explotación, así como de técnicos y de personal especializado, por lo tanto, no sólo estaba en duda la factibilidad del desarrollo de la

2 I El abandono progresivo de la explotación de la Standard y su desplazamiento hacia sus campos en Argentina, Aguas Blancas (Orán) es materia de controversia en la literatura especializada. Algunos puntos de vista seńalan que se trataba de razones técnicas, económicas, de estrategia global de la empresa, y otros de una estrategia coyuntural por causa de la Guerra con el Chaco (Hernández 2013). Un debate acerca del mismo tópico se puede encontrar en la literatura referente a la expropiación petrolera de México, véase, por ejemplo, Haber, Maurer y Razo (2003).

22 La Standard Oil había realizado un relevamiento geológico, que desapareció de Bolivia al momento de la incautación. Sucesivos gobiernos de Bolivia negociaron en varias oportunidades la restitución o compra de lo que consideraban patrimonio del país y documentos que debían revertir al Estado por causa del desahucio de la compañía. El primer Presidente de YPFB, Dionisio Foianini, inició personalmente las gestiones para ello en Buenos Aires, donde estaban las oficinas de la Standard. Finalmente las cartas geológicas y documentos fueron recuperadas al pagarse a la Standard Oil of Bolivia un fondo de indemnización de aproximadamente US\$ I.700.000 en I942. 
industria a futuro, sino su subsistencia. Los rendimientos y resultados financieros de YPFB son una incógnita. La documentación que hemos examinado hasta ahora no registra ningún balance de operaciones ${ }^{23}$, por ende, no es posible realizar cálculos siquiera aproximados, de los resultados financieros, ni tampoco sopesar con datos precisos las interferencias políticas y las corruptelas ${ }^{24}$. Los debates en el Congreso, en particular los realizados entre marzo y abril de 1941, discuten sobre información contradictoria, según unos diputados si bien hubo dispendio de la gerencia durante los dos primeros años, la importación de gasolinas dejaba pérdidas a la empresa, y pese a ello ésta lograba funcionar, mientras otros alegaban que la directiva de YPFB, impuesta por el gobierno de Quintanilla, se encontraba paralizada políticamente y subordinada técnicamente a las directrices de la Cancillería (La Calle 1941). Aun así, se puede suponer que la petrolera estatal boliviana se encontraba en una difícil situación financiera cuando llegó la llamada Misión Bohan (1941), gestionada por el Ejecutivo y su Canciller, sin intervención de YPFB, con el propósito de estudiar la situación económica general del país y de la entidad. A la problemática situación de la empresa petrolera, se sumaba otra limitación estructural de la economía boliviana determinada por la compleja orografía del país, que incidía en sus posibilidades de operación, principalmente dificultando la transportación (ello agravado por la carencia de medios de transporte). En mayo de 1944, un decreto del Ejecutivo separó la función distribuidora de YPFB y creó una efímera Distribuidora de Yacimientos Petrolíferos Fiscales Bolivianos, con el fin de concentrar a YPFB en las labores exploratorias y

23 Otros aspectos de la empresa quedan oscuros. Con respecto a la organización del personal y la estructura de trabajo, la información disponible es inexistente particularmente sobre los cuadros menos calificados. Como los cuadros técnicos eran escasos en el país, se contrataron algunos estadounidenses y rumanos que habían trabajado para la Standard. En el país las prestigiosas escuelas de Minas (en La Paz, Oruro y en Potosí) no habían desarrollado la especialidad, así que, arbitrando los escasos fondos disponibles (becados por YPFB y el Ministerio de Minas) conjuntamente con los apoyos de cooperación internacional, fueron enviados estudiantes, a seguir cursos de ingeniería en petróleos, y geología (entre otras especialidades) a la Universidad Nacional de México, Universidad Nacional de La Plata, a YPF argentina en sus campos de Comodoro Rivadavia y destilería de La Plata, y después, en 1939 a Houston y Oklahoma (Contreras I990a, YPF I936-1949). Cuadros ingenieriles y geólogos, principalmente, fueron contratados entre argentinos de YPF y anglosajones y alemanes destacados en Talara y Lobitos (Royuela Comboni I 996: 84-86).

24 Sabemos que Carlos Quintanilla, sucesor del presidente Busch, dispuso en septiembre de 1939 la intervención de YPFB por una Comisión investigadora e interventora, supervisada por el Ministerio de Minas y Petróleos ante supuestos errores administrativos y gerenciales y corrupción. La documentación generada por la comisión investigadora (localizada hasta la fecha) no permite esclarecer la gestión administrativa ni financiera de YPFB entre I937-I939. Los beneficios a la economía nacional que pudo haber aportado YPFB por la vía de los ahorros de divisas (reducción de importaciones), tampoco están contabilizados en forma confiable en las fuentes examinadas. 
de producción y encomendar al nuevo ente la comercialización.

La distribución de hidrocarburos bolivianos en el mercado interno tanto como su colocación en la región platense, una de sus salidas naturales, dependía de que se lograra la extensión de la red ferroviaria y carretera. Debido a ello, una de las prioridades de los gobiernos del periodo fue buscar la resolución de este problema, mediante el arreglo de convenciones sobre vías férreas y carreteras y la complementación económica con los países vecinos, dada la situación de mediterraneidad del país y la falta de crédito internacional. El tráfico internacional de hidrocarburos requería de medios de transporte específicos, como los buques tanque, tal el caso de otros países productores de Sudamérica como Perú y Argentina, cuyos centros productores se comunicaban con los consumidores por vía marítima (principalmente) y también el caso de los importadores netos (Chile y Uruguay, por ejemplo). Pero en Bolivia la situación geográfica impuso la necesidad urgente de la disponibilidad de vagones tanque, camiones tanque y de oleoductos. Como se señaló anteriormente, la situación del país hacía que fuera más sencillo extraer el petróleo crudo de Sanandita, Camiri y Bermejo, transportarlo por Argentina y reintroducirlo por este país en dirección a los centros de consumo del Altiplano como la ciudad de La Paz y los centros mineros del estaño, que conducirlo directamente desde estos yacimientos a los centros de consumo domésticos.

Estas razones financieras, técnico productivas y de distribución, además de las necesidades geopolíticas de lograr equilibrios frente a sus poderosos vecinos, explican las negociaciones de conexión y diplomacia internacional que emprendieron simultáneamente los gobiernos bolivianos y los directivos de YPFB en distintos momentos entre 1937 a 1947. Encontrar ayuda financiera externa para construir una red de transporte era una prioridad económica general para impulsar el mercado interno y las exportaciones y romper con el atraso secular. Y hallar asistencia técnica y de capital para erigir una industria petrolera nacional, empleando el potencial petrolero como palanca para ese fin, asegurando simultáneamente un mercado para el crudo que se obtuviera, fueron otros propósitos detrás de los tratos de la empresa YPFB con YPF. Cabe resaltar que el país estaba postrado por la concentración de la actividad productiva en la minería del estaño, la crisis financiera arrastrada por años y por los gastos de la guerra con Paraguay ${ }^{25}$, por lo tanto, el petróleo era considerado otro recurso mineral más, que era imperativo negociar en el ámbito regional e internacional.

25 "Bolivia, algunos aspectos interesantes de su economía, I937", en AHCB, Presidencia de la República, I937-I938, fs. I02-I I 3. 


\section{LA DINÁMICA Y MECANISMOS DE NEGOCIACIÓN ENTRE YPF E YPFB}

La conexión entre ambas empresas data del momento de origen de YPFB, erigida en el modelo de la petrolera argentina por un grupo de ingenieros y militares del Chaco que admiraban la experiencia petrolífera argentina y se encontraban vinculados directamente con sus cuadros gerenciales, en particular al ingeniero Ricardo Silveyra quien estuvo al frente de YPF por muchos años. En un comienzo, YPF brindó asesorías técnicas y geológicas, facilitó los exámenes químicos del combustible boliviano en sus laboratorios, y colaboró en la formación y entrenamiento práctico de ingenieros y con prácticas en sus campos y en la refinería de La Plata. En ese momento fundacional, el propio Director de YPFB, Dionisio Foianini, preparó en persona los convenios sobre tráfico de petróleo con Argentina, apalancando en favor de los mismos, mediante cabildeo, al directorio de YPF. Esto se hizo simultáneamente a la firma de acuerdos ferroviarios-petrolíferos con el Brasil, como se expuso en líneas anteriores. La diferencia principal entre ambos convenios estriba en que, mientras en el caso argentino las negociaciones se desplegaban con la empresa petrolera estatal YPF, con Brasil las negociaciones se canalizaban con Itamaraty ${ }^{26}$.

Esta primera experiencia de interacción entre las dos empresas petroleras pretendió establecerse para fortalecer las funciones de exploración, refinación, y comercialización. Se propuso que YPF argentina brindara apoyo técnico a YPFB en la exploración geológica de la cuenca de hidrocarburos compartida con Bolivia, esto es, en la zona fronteriza entre ambas naciones, lindante con la provincia de Salta, particularmente en la región de Tarija y Santa Cruz de la Sierra (Sanandita y Bermejo). Al lado de este apoyo técnico, YPF recibiría petróleo crudo boliviano para refinación en sus destilerías ${ }^{27}$ y se encargaría de su comercialización en el mercado interno argentino. El eje de esta colaboración se proyectaba en el apoyo técnico de YPF a YPFB, en la construcción de un oleoducto que permitiera transportar el crudo boliviano desde los aún poco explotados pozos de Sanandita y de Bermejo a las destilerías argentinas, para su consumo en el mercado argentino ${ }^{28}$. Pero la construcción del oleoducto,

26 A largo plazo, la diferencia también se vería en los resultados que las negociaciones diplomáticas y petroleras con Brasil tuvieron en el desarrollo de la industria petrolera boliviana y de la integración económica del oriente con el Brasil en oposición al noroeste argentino (NOA).

27 Por entonces, la principal, la destilería YPF de La Plata, inaugurada en I925, al lado de otras con menor capacidad de refinación, en San Lorenzo (Santa Fe), Chachapoyas (Salta) y Luján de Cuyo (Mendoza).

28 Algunos sectores de YPFB, en particular su representación en Buenos Aires, eran en I94I partidarios del aprovechamiento de estas conexiones físicas para la colocación 
el equipo técnico y financiamiento que requería, así como su régimen de transporte y fiscalización, fueron materia de largas deliberaciones y enconadas discusiones entre ambas compañías, técnicos, diplomáticos y opinión pública.

En el Cuadro 2, anexo al final por razones de espacio, revisamos el conjunto de los instrumentos de relación bilateral que suscribieron los gobiernos boliviano y argentino entre 1937 y 1945. Son un total de siete acuerdos, convenios y tratados bilaterales, en la mayor parte de los cuales tuvieron importancia definitoria -o sustantiva por lo menos- las negociaciones técnicas entre las dos empresas petroleras estatales. También fue intensa la participación de los Ferrocarriles del Estado Argentino, mediante dictámenes técnicos. La recepción de la opinión, tanto en los Congresos como en las regiones que resultaban directamente influidas por los acuerdos y convenios (los departamentos de Tarija y Santa Cruz de la Sierra en Bolivia, y las provincias de Salta y Jujuy en Argentina) fue otro factor que incidió en las negociaciones (Elío 1940, La Calle 1941, Comité Pro Defensa de los Intereses Cruceños 1942, Ávila 1941). Los instrumentos de vinculación y complementación bilateral firmados entre ambas naciones significaron una opción geopolítica respecto de la vinculación de Bolivia con Brasil, y fijaron una trama básica para el desenvolvimiento de:

1. Obra pública en cooperación: financiamiento y cooperación técnica en la construcción de infraestructura de conexión física entre los mercados argentino y boliviano, mediante ferrocarriles, carreteras y oleoductos.

2. Un rápido corredor mercantil atlántico, en condiciones preferenciales fiscales y arancelarias para los productos bolivianos y una opción de mercado para las exportaciones argentinas a ese país.

3. Un mecanismo de transporte y flujo energético en aras de una potencial complementación.

4. Una opción recíprocamente conveniente, por lo menos temporalmente, para la cooperación petrolífera: el intercambio de combustibles y equipo y maquinaria a cambio de financiamiento y experiencia técnica en la industria petrolera, justo en medio de una coyuntura internacional de restricción de importaciones de bienes

del crudo boliviano que se pudiera obtener en el mercado uruguayo, controlado por la ANCAP desde I93I. Los proyectos ideados superficialmente entre I94I y I943 no plasmaron, pese a contar con el interés, en esa coyuntura de guerra mundial y escasez y racionamiento de combustibles, de la gerencia de la ANCAP. AHCB, Yacimientos Petrolíferos Fiscales, volúmenes I939-1945. 
de capital y combustibles como lo fue el periodo 1942-194629.

5. Un mecanismo que asegurara la refinación de combustibles bolivianos en plantas argentinas, y la regulación de mecanismos claros para la fijación de costes y precios.

Dejando a un lado las orientaciones y prioridades geopolíticas de los gobiernos de estos países, materia de otro estudio específico ${ }^{30}$, cabe señalar que las prioridades estratégicas y comerciales de estos dos actores involucrados en la negociación de los convenios sobre tráfico y comercio de hidrocarburos, YPF e YPFB, particularmente en la coyuntura de 1941-1942, eran muy distintas. Con propósitos de exposición podría esquematizarse de esta manera:

1. Mientras YPF fue un actor consolidado en la economía argentina, con iniciativa propia en el diseńo de una estrategia de aproximación y de desenvolvimiento industrial y comercial, que representaba necesidades y prioridades de largo alcance que tendrían continuidad tras el paso de las décadas subsiguientes, YPFB sólo encontró una instancia coyuntural para resolver los problemas que planteaba su desenvolvimiento industrial y mercantil en la posguerra del Chaco.

2. La definición de la estrategia de ambas compañías fue, entre 1937 y 1941, nutrida por prioridades diferentes. Por un lado, YPFB trataba -mientras no dispusiera de otra alternativa- de obtener apoyo técnico y financiero, y mercados, para dar salida a un recurso que permanecía casi en estado potencial, y a la vez impulsar el despegue de la industria petrolera estatal. Los propósitos de la empresa YPFB eran, puntualmente: 1) abrir el mercado platense, no sólo el argentino sino además el oriental, con la posibilidad de acceso a las compras de la ANCAP; 2) obtener colaboración, medios técnicos y financieros para sus planes de:

- Formación y entrenamiento de personal técnico especializado en petróleos.

- Perforaciones y exploraciones: recuperación y desarrollo de viejos y nuevos yacimientos y pozos. Particularmente, un plan para Sanandita, para Camiri, y para Bermejo, los principales

29 Ver los registros en Foreign Relations of the United States, I937-I945, Bolivia, y 1939-I945, Argentina.

30 De lado de Argentina: "Se evita que Brasil realice esta conexión con antelación y que lleve estos combustibles para su uso", Informe del ingeniero Emilio Rebuelto, asesor Técnico del Plan ferroviario con Bolivia, AHCA, Bolivia, 1937, leg. I3, Anexo III. Véase Figallo I996, Zanata 2005, y para Bolivia Holland 1967. 
yacimientos hasta la fecha.

- Construcción de Infraestructura de refinación: destilerías (planeación y construcción).

- Construcción de infraestructura de transportación como oleoductos y ferrocarriles hacia el Plata y otras opciones de rutas (Mariaca 1944: 50-72). A tal efecto la delegación boliviana que participó en la Conferencia intergubernamental, consiguió fijar las bases de un acuerdo regional sobre la construcción de oleoductos internacionales y la liberación arancelaria a su tráfico (Secretaría de la Delegación de Bolivia 1941).

Por el contrario, la empresa YPF tenía otras necesidades urgentes antes que asistir a YPFB. En el orden interno, necesitaba resolver las limitaciones del marco regulatorio argentino y desarrollar mecanismos técnico productivos para conseguir acceso seguro y exclusivo a la cuenca compartida del recurso petrolífero y gasífero con Bolivia (el noroeste, particularmente la provincia de Salta, donde existían yacimientos y refinerías de petróleo). Para ello, requería control total sobre esos yacimientos de Salta, e incrementar la exploración y explotación de toda la región norteña. A los técnicos de YPF interesaba determinar en qué medida el crudo boliviano podía abastecer la creciente demanda de todo el Noroeste, a precios más económicos que el que se conducía desde la Patagonia y el Atlántico. Todo ello implicaba, a su vez, asuntos de orden internacional: la posibilidad de interferir y bloquear el desenvolvimiento de una posible integración petrolífera boliviana con Brasil, asunto que no quedó inadvertido para la dirección de YPF. Otras consideraciones más amplias de mercado, acerca de las ventajas arancelarias, comerciales e industriales generales para Argentina en la vinculación ferroviaria y caminera fronteriza con Bolivia, no eran asunto de YPF, aunque sí de otros actores intervinientes en estas negociaciones, como los técnicos de los Ferrocarriles del Estado, y del Ministerio de Economía, por ejemplo.

Empero, estas prioridades de ambas empresas petroleras estatales se vieron desbordadas a mediados de 1941, cuando irrumpieron los problemas de alineamiento diplomático, de abastecimiento, de racionamiento y economía de guerra. De la mano de ellos se fijaron racionamientos de combustibles y equipo (Administración de Petróleo para la Guerra, o Petroleum Administration for War, PAW, en inglés, 1941-1946), arribó a Bolivia una misión estadounidense, encabezada por Merwin Bohan a La Paz. Dicha misión contó con el experto en petróleos del Departamento de Estado y consejero del PAW, Max Thornburg. 
Desde la perspectiva del gobierno boliviano, los imperativos fueron claros: sin combustibles, el país jamás podría aportar los materiales minerales estratégicos para la guerra ni inscribirse en los programas de cooperación económica hemisférica. Del lado argentino, la escasez de combustibles sólidos e hidrocarburos impuesta por la contienda despejó el escenario y aclaró lo urgente. El petróleo boliviano podría ser lo que varios técnicos señalaban desde 1937: una verdadera reserva suplementaria para YPF. Fue entonces cuando la gerencia de YPF se vio empujada a buscar por todos los medios el petróleo boliviano que parecía desdeñar meses atrás, de forma de contrarrestar la abrupta caída de las importaciones de crudo por el Atlántico. Gracias a la conexión boliviana, en esa coyuntura YPF podría acceder a importaciones de combustible sin depender de las cuotas y racionamientos de la comercialización atlántica, libre de las limitaciones de transportación y fletes. En el terreno de la construcción de infraestructura de conexión y transportación energética, también YPF se encontró en 1942 frente a las paradojas de la guerra: tener que reclamar al gobierno boliviano y a YPFB por obtener de los Estados Unidos facilidades de equipamiento de acero y metales para tubería, cañerías y perforadoras que habían sido restringidas severamente a Argentina por la situación bélica y en represalia por su negativa diplomática a renunciar a la neutralidad.

La misión económica estadounidense presentó un Plan de Fomento General ofertando recursos del Import Export Bank cuya oferta para Bolivia, a cambio de los compromisos de provisión de estaño para la Reserva Federal de Metales, superaban los US\$20.000.000 y formulando un plan específico para el petróleo (véase Cuadro 2, Bohan 1942). La inyección de fondos que fluyó después, junto con el levantamiento de las restricciones por parte de los Estados Unidos para la importación de maquinaria destinada a construir caminos, vías férreas y una refinería, podrían haber modificado notoriamente la condición contable y financiera y la capacidad productiva de la empresa ${ }^{31}$.

Así, mientras la misión Bohan estudiaba el terreno, YPFB lograba que YPF consintiera en construir los oleoductos necesarios, a cambio de cañerías estadounidenses que Bolivia aportaría y que Argentina pagaría a precio de costo. Finalmente YPF resolvía, mediante la negociación con YPFB, atender necesidades de la guerra. Entre ellas se contaron no sólo crudo para refinar, sino además el equipo necesario y la posibilidad de gestionar acuerdos secundarios sobre caucho y goma, productos sin los cuales la estatal argentina no lograba operar, ni tampoco el conjunto de la economía de ese país. La guerra había privado a Argentina también de buena parte de las importaciones de caucho brasileñas, debido a los

3 I Que diez ańos después, en I954, alcanzó a satisfacer el total de la demanda interna. 
programas de cooperación hemisférica suscritos por Brasil, entre ellos la campaña del caucho, que destinaba su producto al esfuerzo bélico de los aliados. Sin el producto habitualmente importado de Brasil, la actividad petrolera y económica general argentina auguraba rápido colapso ${ }^{32}$.

Como se ve, las negociaciones entre estas dos empresas petroleras fueron apalancadas por las limitaciones coyunturales -las restricciones al comercio de metales, maquinaria, insumos y combustibles desde 1941-1942-, y también estranguladas por éstas. Por eso, consideraciones relacionadas con la seguridad energética y estrategia industrial motivaron el cambio en YPF en favor de una intensa cooperación con YPFB. Sin embargo, el horizonte de recíproco beneficio que se abrió recién a comienzos de 1942 como resultado de las alteraciones de los mercados, del contexto internacional y de seguridad Hemisférico en 1942, declinó con rapidez en la posguerra y se asfixiaría entre el "abrazo peronista" y "El viaje de Perón" (Zanata 2005) y sus encuentros y desencuentros con el MNR.

\section{LOS RESULTADOS VISIBLES DE LA INTERACCIÓN}

La interacción negociadora entre ambas empresas estatales, de cara a la firma de este conjunto de acuerdos fue continua, particularmente desde 1940 en adelante, y se desarrolló en Buenos Aires, no en La Paz. A excepción del caso de los convenios ferroviarios, no se crearon comisiones específicas y las negociaciones se efectuaron mediante reuniones ad hoc entre distintos cuadros directivos gerenciales y técnicos de YPF argentina, y el ingeniero representante de YPFB en ese país, Juan Pinilla. Las fuentes periodísticas sugieren que el Directorio de YPFB estuvo en 1941 dividido acerca de las gestiones en pos de la vinculación con argentina a través de YPF (La Calle 1941), pero la documentación diplomática examinada está sesgada y no brinda estos indicios. Posteriormente, entre 1944 y 1945 Jorge Lavadenz, Presidente del Directorio de la empresa YPFB, negoció con las autoridades de YPF los puntos y términos controversiales. La embajada de Bolivia en Buenos Aires y, en repetidas ocasiones, el Ministro de Relaciones Exteriores de turno, fueron otros actores implicados y participantes en las negociaciones del lado boliviano, aunque generalmente, en lo que concernía a YPFB, el vocero era el representante de la empresa en Buenos Aires. Junto a los técnicos de YPF también fueron muy importantes las gestiones de la gerencia de los Ferrocarriles del Estado Argentino.

Además de las negociaciones muy demoradas y complejas sobre las conexiones ferroviarias, hubo varios puntos controversiales en las negociaciones de YPF e YPFB, que trabaron sistemáticamente sus

32 Sobre este punto, véase AHCB, YPFB, volúmenes I939-I945. 
progresos, y que fueron superadas durante el transcurso del año crítico de 1942, cuando cada mes restringía más el acceso de YPF a combustibles importados:

1. La negociación de los mecanismos para la fijación de los precios del crudo boliviano colocado en el mercado argentino, habida cuenta que hasta 1942 hubo prohibición de importación de crudo para YPF sin autorización expresa puntual, en función de los acuerdos con las compañías importadoras y productoras británicas y estadounidenses para controlar los precios internos. Esta barrera desapareció en el contexto de la conflagración.

2. El cálculo del costo de transportación del combustible crudo desde la boca del pozo a las refinerías argentinas para su procesamiento.

3. La localización del proceso de refinación: el lugar de refinación. Esta decisión era crítica, debido al alto costo de la transportación por tierra desde el sur de Bolivia y la saturación del mercado de combustibles del noroeste argentino. Lo lógico era que el crudo boliviano se refinara en Salta, pero la destilería salteña no tenía la capacidad. San Lorenzo (Santa Fe), la siguiente más cercana, si tenía capacidad, pero el costo de transporte mientras no hubiera oleoducto de conexión, tornaba inviable esa opción. Finalmente, se tomó la salomónica decisión de que el combustible viajara por vía fluvial en chatas desde Embarcación (Bermejo) a la destilería de La Plata (localizada en el río de la Plata).

4. Los acuerdos, disposiciones, exenciones y privilegios arancelarios para este tráfico.

5. Los aportes financieros del gobierno argentino a los programas de desarrollo de YPFB.

Estas negociaciones generaron incansables reuniones, demoras y rechazos reiterados de YPF a las gestiones de YPFB, y la participación técnica de otras organizaciones, como Ferrocarriles del Estado (Argentina). La complicada dinámica negociadora, primera experiencia de actividad internacional de ambas empresas, no produjo en sí misma ni reorganización ni especialización institucional en éstas ${ }^{33}$. Tampoco provocó el diseño de instituciones especializadas, intergubernamentales ni interempresariales, que pudieran destinarse en forma exclusiva a supervisar, dar seguimiento

33 Las reformas a YPFB y su organización administrativa y operativa se dieron como consecuencia de los programas de fomento y desenvolvimiento petrolero que arrancaron con posterioridad al Plan Bohan, como consecuencia de su aplicación. YPF argentina también colaboró con la ANCAP en este mismo periodo. 
y controlar a la interacción binacional y empresarial petrolera. Asimismo, no hubo mecanismos claros para: 1) la administración de los flujos de comercio que se establecieran; 2) la deliberación y consulta en torno a los conflictos que se pudieran suscitar en asuntos comerciales, arancelarios, financieros y técnicos (estos tres últimos particularmente abundantes, en la medida en que implicaban a varias agencias de gobierno de los dos países y su Banca central al lado del Export-Import Bank); 3) los ajustes que imponía el proceso de aplicación, lenta y demorada de los convenios; y 4) la toma de decisiones. Ello se aprecia además al observar las memorias de YPF, en las que, a diferencia de su Boletín de prensa, no se consigna ningún apartado específico para referir a las gestiones con YPFB.

El resultado fue un empantanamiento de la operación y puesta en práctica de los numerosos acuerdos suscritos, que se agravó posteriormente, cuando la extrema politización e ideologización de la diplomacia peronista sudamericana entre 1945 y 1953 , por lo menos, provocó una catarata de malentendidos regionales y hemisféricos, especialmente en los tratos de Bolivia con Argentina (Zanata 2005). Los acuerdos y convenios, que no habían sido resultado exclusivo de aproximaciones políticas entre los gobiernos boliviano y argentino, sino que involucraron a dos petroleras estatales sudamericanas y a una pluralidad de actores (instituciones, actores políticos y e intereses económicos), representando además una experiencia de aproximación bilateral entre dos naciones y economías vecinas pero distantes tradicionalmente, terminaron corriendo la suerte de los negocios políticos en el mundo polarizado de la posguerra. También es preciso señalar que las conexiones internacionales promovidas directa o indirectamente por YPFB en la región platense tuvieron amplios consecuencias políticas, que no hemos tratado aquí. Al movilizarse intereses empresariales y regionales (azucareros, petroleros, ferroviarios y obreros de las fronterizas Tarija, Santa Cruz de la Sierra, Salta y Jujuy, a ambos lados de la frontera) ${ }^{34}$, surgieron dificultades de orden político, jurídico, aduanero y comercial estructural.

Empero, vistas desde Bolivia, para YPFB las negociaciones en pos de una conexión con YPF no fueron infructuosas en el terreno económico, y tuvieron más resultados beneficiosos que pérdidas. Los planes de formación de recursos técnicos resultaron al final exitosos, desafiando las previsiones más escépticas. Con ello, en pocos años se perforaron nuevos pozos y se reactivaron los abandonados y la producción se incrementó entre 1932 y 1948 a una tasa de crecimiento promedio anual de 10,4\% (Mariaca 1966: 88-89, Almaraz 1958: 173). Si bien las importaciones de combustibles procedentes predominantemente de Perú y Estados Unidos no se redujeron en forma drástica como era esperado, aumentó lentamente el abasto de la

34 Mismos que no hemos estudiado aquí y que merecen atención futura. 
demanda interna, de manera que si en 1937 el consumo atendido por YPFB no pasaba del 25\% de la demanda total, en 1939 cubrió el 40\% y $50 \%$ de ésta respectivamente (Mariaca 1944).

Como vimos, las miras de YPFB no estaban en el mercado interno. La estrategia persistente de la estatal boliviana durante todo el periodo aquí estudiado, fue su orientación a la exportación antes que al abasto interno, por lo menos hasta fines de $1942^{35}$. Las razones eran justamente, convertir el petróleo exportado en un recurso generador de riqueza e impulsor de la modernización de la economía doméstica, una moneda de cambio para obtener recursos financieros y técnicos, no obstante los hidrocarburos eran un recurso potencial, no disponible para la exportación en 1937 ni en 1943 en Bolivia. Lo anterior resulta paradójico en la medida en que lo que escaseaba era el petróleo dado el abandono de las concesiones y las limitaciones antes señaladas, a fin de cuentas, se trataba de negociaciones más afincadas sobre posibilidades futuras de rendimiento de un recurso que aún no se había aprovechado del todo.

Pero, el propósito de colocar crudo en Argentina fue alcanzado, y prefiguraba la mucho más tardía conexión y complementación gasífera entre ambas economías. Si bien las primeras exportaciones de crudos y fuel de 1941 de Bolivia a Argentina no tuvieron peso estadístico, su crecimiento es visible a partir de 1945-1948 (Unión Panamericana 1956: 66). La producción total de crudo en barriles aumentó entre 1942 y 1946 aproximadamente en un 18\% (Vargas 1996: 32). En diez ańos, la perforación de pozos se había incrementado como muestra el hecho de que el metraje perforado pasó, sólo entre 1939, de 1.160 a 3.413 metros en 1946 (Royuela Comboni 1996: 226). Se habían realizado estudios divergentes entre sí- en reconocimiento de las reservas petrolíferas del país. Las negociaciones prolongadas en pos de conexiones con el mercado argentino, habían posibilitado el logro de mayor experiencia técnica en el cálculo de costos, de factibilidad, estudios de mercado y desarrollo de planes de inversión. El primer oleoducto se terminó en 1949 conectando Camiri con Sucre, donde se instaló una refinería en 1949, al lado de otras tres: Camiri (renovada y ampliada en 1947), Bermejo (construida en 1944 y ampliada en 1952) y Cochabamba (1950). Las obras de infraestructura se completaron -en ese periodo de posguerra y de la presidencia de Villarroelcon el inicio de la construcción del poliducto Cochabamba-Oruro-La Paz (Vargas 1996: 39). Como resultado, para 1954, YPFB abastecía el 83,6\% del consumo interno total (Vargas 1996: 37).

35 AHCB, YPFB, volúmenes I939-I945. 


\section{ANEXO}

\section{Cuadro 1bis: Instrumentos bilaterales firmados entre Argentina y Bolivia, 1937-1945}

\begin{tabular}{|c|c|c|c|c|c|}
\hline Instrumento & Fecha & Materia & $\begin{array}{c}\text { Disposición } \\
\text { principal }\end{array}$ & $\begin{array}{c}\text { Incluye } \\
\text { negociación } \\
\text { entre YPF/ } \\
\text { YPFB }\end{array}$ & $\begin{array}{c}\text { Ratificado } \\
\text { Sí-No }\end{array}$ \\
\hline $\begin{array}{l}\text { Acuerdo } \\
\text { sobre tráfico } \\
\text { fronterizo }\end{array}$ & $17 / 09 / 1937$ & $\begin{array}{l}\text { Integración y } \\
\text { comunicación } \\
\text { fronteriza }\end{array}$ & $\begin{array}{l}\text { Regula tráfico } \\
\text { Regula aduanas }\end{array}$ & Sí & Sí \\
\hline $\begin{array}{l}\text { Convención } \\
\text { preliminar } \\
\text { ferroviaria }\end{array}$ & $17 / 09 / 1937$ & $\begin{array}{c}\text { Integración } \\
\text { ferroviaria }\end{array}$ & $\begin{array}{c}\text { Regula } \\
\text { construcción } \\
\text { ferrocarril } \\
\text { Yacuiba-Santa } \\
\text { Cruz (Camiri) } \\
\text { Establece } \\
\text { Comisión Mixta } \\
\text { ferroviaria } \\
\text { binacional }\end{array}$ & $\begin{array}{l}\text { No en } \\
\text { principio }\end{array}$ & Sí \\
\hline $\begin{array}{l}\text { Convenio } \\
\text { sobre tráfico de } \\
\text { petróleo }\end{array}$ & $19 / 11 / 1937$ & $\begin{array}{c}\text { Comercio de } \\
\text { hidrocarburos } \\
\text { bolivianos } \\
\text { en mercado } \\
\text { argentino }\end{array}$ & $\begin{array}{l}\text { Construcción de } \\
\text { infraestructura } \\
\text { de transportación } \\
\text { y almacenaje } \\
\text { hidrocarburos } \\
\text { bolivianos } \\
\text { en territorio } \\
\text { argentino- } \\
\text { Establece } \\
\text { negociación } \\
\text { aduanera } \\
\text { importación } \\
\text { combustibles } \\
\text { bolivianos en } \\
\text { Argentina. }\end{array}$ & Sí & No \\
\hline $\begin{array}{c}\text { Convenio sobre } \\
\text { construcción de } \\
\text { oleoductos } \\
\text { (Conferencia } \\
\text { Regional del } \\
\text { Plata)* }\end{array}$ & $6 / 02 / 1941$ & $\begin{array}{l}\text { Construcción de } \\
\text { oleoductos en la } \\
\text { cuenca platense }\end{array}$ & $\begin{array}{c}\text { Regulación de } \\
\text { construcción } \\
\text { oleoductos y } \\
\text { de exenciones } \\
\text { arancelarias } \\
\text { para el tráfico } \\
\text { internacional de } \\
\text { hidrocarburos, } \\
\text { por vía terrestre } \\
\text { (ductos) entre } \\
\text { países vecinos. }\end{array}$ & Sí & No \\
\hline
\end{tabular}


Tratado sobre vinculación ferroviaria

Convenio que

fija los términos de un contrato entre los YPF argentinos y bolivianos sobre compra-venta de petróleo
Fija

financiamiento

y administración

conjunta

argentino/

boliviano de la

obra.

Establece

financiamiento

ferroviario de

$\$ 2.000 .000$

argentinos

contra pago

con exportación

a Argentina

de petróleo

boliviano de

Bermejo, para

su refinación y

comercialización.

Establece

términos,

cantidades, plazos

y mecanismos

de fijación de

precios para las

obligaciones de

compra y venta

Acuerdo de obligaciones de compra y venta de combustibles líquidos entre las empresas estatales
No

Sí.

Publicado

Todo 1941

y 1942

Notas

reversales

14/08/1941 de hidrocarburos

entre las

empresas.

Establece

obligaciones de

transportación

y compromisos

financieros y

técnicos para la

construcción de

un oleoducto

Bermejo-Río

Pescado-Orán

(Bolivia-Salta) 
Horizontes, Negociaciones y Disyuntivas en los Tratos de YPFB e YPF

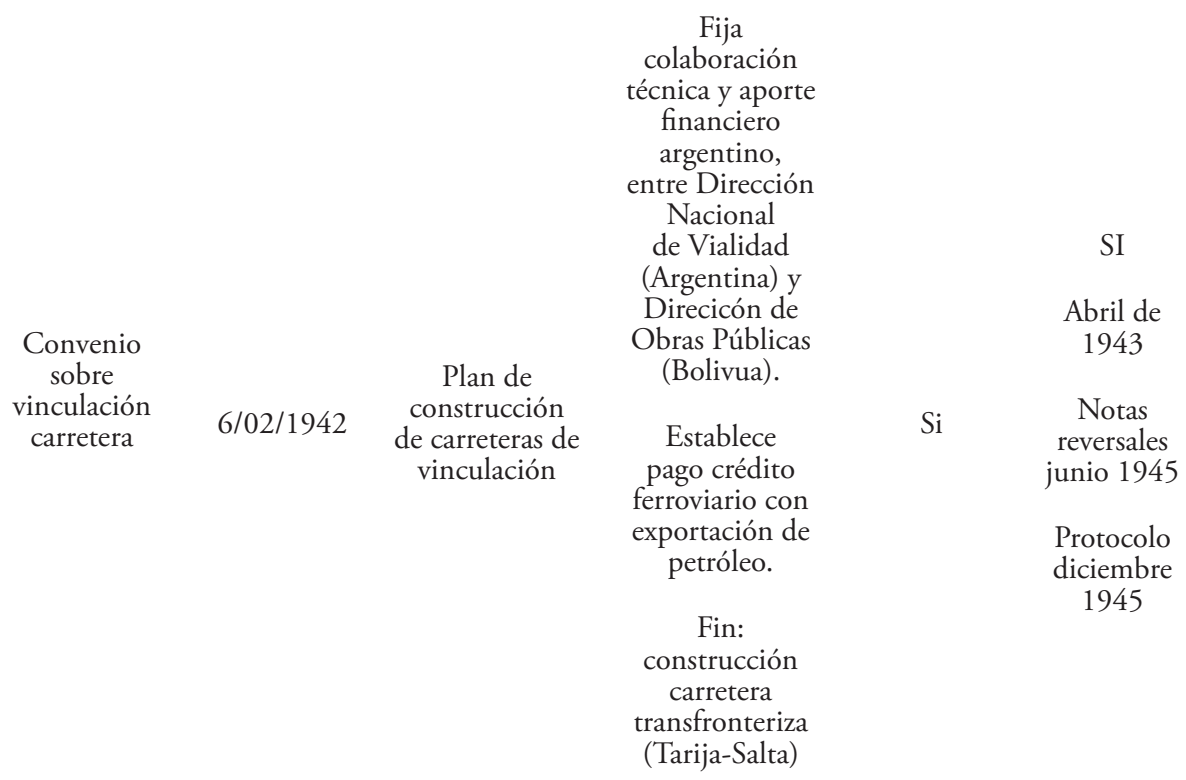

* Multilateral.

Fuente: Elaboración propia con base en AHCB. Yacimiento Petrolifero Fiscal Boliviano, 1939-1945, Moreno Quintana (1945), YPF Boletín (19371945), Avila (1941). 


\section{Cuadro 2: Propuestas del Plan Bohan para YPFB. Tres caminos de acción}

Plan intensivo de perforación

\author{
Plan para resolver abasto de \\ gasolinas \\ (el 94\% de las gasolinas consumidas \\ es importado)
}

Plan para la venta, exportación y distribución de combustibles
- Desarrollo yacimientos productivos y reservas en campos Sanandita, Camiri y Bermejo.

- Exploración otras zonas potencialmente productoras de crudo: para incrementar reservas.

- Propuestas y opciones para importación combustible por la vía más rápida y económica.

- Elaboración de Proyectos y evaluación de costos y factibilidad para la construcción de una refinería.

- Proyectos de fomento caminero y ferroviario (plasma en la Corporación Boliviana de Fomento).

- Gestión de acuerdos de comercio y transporte con los países vecinos, Argentina y Brasil.

- Construcción de infraestructura para la transportación: oleoductos hacia Argentina, 1949, ferrocarriles al Brasil; Instalación de cañerías de transporte de combustibles.

Fuente: Bohan (1942). 


\section{REFERENCIAS}

Almaraz, S. (1958). Petróleo en Bolivia. La Paz: José Camarlinghi Editor.

Amatori, F. (2009). Bussines History: State of Art and Controversies. Revista de Historia Industrial, 39, 17-35

Administración Nacional de Combustibles, Alcohol y Pórtland (ANCAP). (2006). Lo Que Nos Mueve es Todo un País, 1931-2006. 75 Años ANCAP. Montevideo: ANCAP.

Ávila, F. (1941). Bolivia en el Concierto del Plata. México: CVLTURA.

Baldrich, A. (1934). El Problema del Petróleo y la Guerra del Chaco. Buenos Aires: Edición de la Revista Americana.

Barbero, I., y Jacob, R. (Eds.). (2008). La Nueva Historia de Empresas en América Latina y España. Buenos Aires: Temas Grupo Editorial.

Belini, C. y Rougier, M. (2008). El Estado Empresario en la Industria Argentina. Conformación y Crisis. Buenos Aires: Manantial.

Beltrán, C. (1944). Defensa del Petróleo Boliviano. Oruro: Tipografía Segura.

Bertolini, R. y Travieso, E. (2012). El Concepto de Comunidad Energética Regional y su Pertinencia para Discutir la Integración desde Uruguay. Ponencia presentada en el III Congreso Latinoamericano de Historia Económica, 23 al 27 de octubre, Bariloche.

Bohan, M. Informe de la Misión Económica de los Estados Unidos A Bolivia. La Paz.

Boneo, H. (1979). Planificación, Presupuesto y Empresas Públicas en América Latina. Estudios CEDES, 2, 602-622.

Bucheli, M. (2010). Major Trends in the Historiography of the Latin American Oil Industry. Business History Review, 84, 339-362.

Campero, F., Toranzo, C., Patińo J., Bastos, I. y Anaya, A. (1999). Bolivia en el Siglo XX. La Formación de la Bolivia Contemporánea. La Paz: Harvard Club de Bolivia. 
Carrillo, H. (1922). El Ferrocarril al Oriente Boliviano. Algunos Antecedentes. La Convención. Notas Personales. Buenos Aires: Imprenta y Casa Editora Coni.

Carrizo, C. y Ramousse, D. (2010). Dinámicas energéticas e integración regional en el noroeste argentino y el sur boliviano. Revista de Geografía Norte Grande, 45, 51-62

Centro de Pesquisa e Documentação de História Contemporânea do Brasil (CPDOC). (1941). Algunos Aspectos sobre la Situación Real de Y.P.F.B. [Folleto]. Fondo Horta Barbosa, V.P. 1938.07.07 (Pasta IX). Zumelzu: autor.

Ceppi, N. (2010). La Temática Energética en las Relaciones entre Argentina y Bolivia. Acuerdos y Contrariedades por el Gas Natural. Foro Internacional, 50, 5-34.

Comín, F. (1995). La Empresa Pública en la España Contemporánea: Formas Históricas de Organización y Gestión (1770-1995). Madrid: Fundación Empresa Pública.

Comité Pro Defensa de los Intereses Cruceños. (1942). Argentina y Bolivia y su Vinculación Ferroviaria Efectiva en el Oriente. La Paz: Alcaldía Municipal de Santa Cruz de la Sierra, Artística.

Contreras, M. (1990a). Debt, Taxes and War: The Political Economy of Bolivia, c. 1920-1935. Journal of Latin American Studies. 22, 265-287.

. (1990b). The Formation of a Technical Elite in Latin America. Mining Engineering and the Engineering Profession in Bolivia, 1900-1954. Tesis de doctorado, Columbia University. Nueva York, Estados Unidos de América.

Cote, E. (2011). The Nature of Oil in Bolivia, 1896-1952. Tesis de doctorado, University of California. Davis, Estados Unidos de América.

Cramer, G. (1998). Argentina Riddle: The Pinedo Plan of 1940 and the Political Economy of the Early Wars Years. Journal of Latin American Studies, 30 (3), 519-550.

Cuervo, Á. (2001). La Empresa Pública, 1950-2000. Revista de Historia industrial, 19-20, 339-345. 
Elío, T. (1940). Las Vinculaciones Ferroviarias entre Bolivia y Argentina, son la Base de su Futura Solidaridad Económica. Conferencia pronunciada en el Museo Social Argentino, por el Ministro Plenipotenciario de Bolivia, Tomás Manuel de Elío a invitación del Instituto Cultural Argentino-Boliviano, 5 de julio, Buenos Aires, Argentina.

Figallo, B. (1996). Bolivia y la Argentina: Los Conflictos Regionales durante la Segunda Guerra Mundial. Estudios Interdisciplinarios de América Latina y el Caribe, 7, 1996.

Foianini, D. (1991). Misión cumplida. Bolivia: Imprenta Sirena.

Gadano, N. (2006). Historia del Petróleo en la Argentina, 1907-1955: Desde los Inicios hasta la Caida de Perón. Buenos Aires: EDHASA.

Garibay, D. (2006). Un análisis político de la integración en América: entre Estrategias Nacionales y Contextos Hemisféricos. En Rousseau, I. (Comp.), ¿Hacia la integración de los mercados petroleros en América? México: El Colegio de México.

Gratius, S. (2008). MERCOSUR Y NAFTA. Instituciones y Mecanismos de decisión en procesos de Integración Asimétricos. Madrid: IberoamericanaVervuert.

Great Britain. (1944). Bolivia. Review of Commercial Conditions, December 1944. London: Department of Overseas Trade.

Hernández, J. L. (2012). Una Guerra Fratricida: El Conflicto por el Chaco Boreal (1932-1935). Pacarina del Sur, 3 (10). Disponible en http:// www.pacarinadelsur.com/home/abordajes-y-contiendas/370-unaguerra-fratricida-el-conflicto-por-el-chaco-boreal-1932-1935 [30-032013].

Holland, E. (1967). A Historical Study of Bolivian Foreign Relations: 19351946. Tesis de doctorado, American University. Washington, Estados Unidos de América.

Hoz de Vila, V. (1988). Petróleo y su Legislación en Bolivia. Bolivia: Los Amigos del Libro.

Jacob, R. (1979). Inversiones Extranjeras y Petróleo. La Crisis del 29 en el Uruguay. Montevideo: Fundación de Cultura Universitaria. 
Kaplan, M. (1965). Desarrollo Económico y Empresa Pública. Buenos Aires: Ediciones Macchi.

(1967). La Empresa Privada y la Empresa Pública en la Integración Fronteriza. La Empresa Multinacional. Sextas Jornadas Chilenas de Derecho Público. Santiago: Universidad de Chile, Facultad de Ciencias Jurídicas y Sociales, EDEVAL.

Klein, H. (1969). Parties and Political Change in Bolivia, 1880-1952. London: Cambridge University Press.

. (1993). Orígenes de la Revolución Boliviana La Crisis de la Generación del Chaco. México: CONACULTA.

Limpias Ortiz, V. (2009). Las Ferrovias y la Carretera que Transformaron el oriente Boliviano, 1938-1957. Santa Cruz de la Sierra: El País.

Lorandini, I. (2006). El Nacionalismo en Bolivia de la Pre y Posguerra del Chaco (1910-1945). Bolivia: Plural.

Malgesini, G. y Álvarez N. (1982). Cereales y Combustibles. Problemas de la Economía Argentina durante la Segunda Guerra Mundial. Ponencia presentada en las Jornadas de Historia Económica Argentina, agosto, Río Cuarto.

Mariaca Muñoz, G. (1944). Reseña sobre la Industria Petrolifera de Bolivia. La Paz: Norte.

Mariaca, E. (1966). Mito y Realidad del Petróleo Boliviano. La Paz: Editorial Los Amigos del Libro.

Moreno Quintana, L. y Torres C. (1945). Los Tratados de Comercio de la República Argentina Buenos Aires: Imprenta de la Universidad.

Orieta, F., Morinelli, M. y Ragno, R. (1987). Notas sobre la Intervención Estatal en los Inicios de la Industria Petrolera (1880-1916). Boletín del Departamento de Historia, 8, 47-74.

Ostria Gutiérrez, A. (1946). Una Obra y un Destino. La Politica Internacional de Bolivia después de la Guerra del Chaco. Buenos Aires: Editorial Ayacucho.

Phelps, D. (1939). Petroleum Regulation in Temperate South America. The American Economic Review, 29, 48-59. 
Philip, G. (1989). Petróleo y Politica en América Latina. México: Fondo de Cultura Económica.

Ramos, E. (1927). El Petróleo en la República Argentina. Su Legislación. Buenos Aires: Valerio Abeledo Librería Jurídica.

Rapoport, M. (2005). Historia Económica, Politica y Social de la Argentina (1880-2003). Buenos Aires: EMECÉ.

Rousseau, I. (Comp.). ( 2006). ¿Hacia la Integración de Mercados Petroleros en América? México: El Colegio de México.

. (Coord.). (2010). América Latina y Petróleo, Los Desafíos Políticos y Económicos de Cara al Siglo XXI. México: El Colegio de México.

Rout, L. (1970). Politics of The Chaco Peace Conference. Austin: University of Texas Press, Institute of Latin American Studies.

Royuela Combiani, C. (1996). Cien Años de Hidrocarburos en Bolivia (1896-1996). Bolivia: Los Amigos del Libro.

Rubio, M., Yáñez, C., Folchi, M. y Carreras, A. (2010). Energy as an Indicator of Modernization in Latin America, 1890-1925. Economic History Review, 63, 769-804.

Secretaría de la Delegación de Bolivia. Conferencia Regional de los Países del Plata (Montevideo, 21 de enero-6 de febrero de 1941). La Paz: Secretaría de la Delegación de Bolivia.

Silenzi, A. (1955). El petróleo Argentino. Buenos Aires: Colección Problemas Nacionales.

Smith, P. (1971). Bolivian Oil and Brazilian Economic Nationalism. Journal of Inter-American and World Affairs, 13, 166-181.

Solberg, C. (1986). Petróleo y Nacionalismo en Argentina. Buenos Aires: Hyspamérica.

Solberg, C. (1982). Entrepreneurship in Public Enterprise: General Mosconi and the Argentine Petroleum Industry. Business History Review, 56, 380-399.

Spencer, J. (1996). Oil, Politics and Economic Nationalism in Bolivia, 1899-1942. The Case of the Standard Oil Company and Bolivia. Tesis 
de doctorado, University of California, Los Angeles, Estados Unidos de América.

Superintendencia de Bancos. (1938). Memoria de la Superintendencia de Bancos Correspondiente a los Años de 1937-1938. La Paz: Superintendencia de Bancos.

Unión Panamericana. (1956). The Foreign Trade of Latin America since 1913. Washington: Unión Panamericana.

United States Tariff Commission. (1942). The Foreign Trade of Latin America. Three Parts (I-III); Part I Trade of Latin America with the world and with the United States. Report No. 146. Second Series.

Valdaliso, J.y López. S. (2000). Historia Económica de la empresa. Barcelona: Crítica.

Vargas, A. (1996). Y.P.F.B. Entre Nacionalistas y liberales. Bolivia: Los Amigos del Libro.

Wilkins, M. (1974). Multinational Oil Companies in South America in the 1920's: Argentina, Bolivia, Brazil, Chile, Colombia, Ecuador and Perú. Business History Review, 48, 414-446.

Yacimientos Petrolíferos Fiscales Bolivianos (YPFB). (1973). YPFB. La Paz: Boliviana.

Yacimientos Petrolíferos Fiscales (YPF). (1932) Desarrollo de la industria petrolifera fiscal, 1907-1932. Buenos Aires: Talleres Jacobo Peuser Ltda.

- (1936-1949) Boletín de Informaciones Petroleras. Buenos Aires: Yacimientos Petrolíferos Fiscales.

(1943). Memoria de YPF correspondiente al Año 1942. Boletín de Informaciones Petroleras, 228, 1-109.

. (1972). Una Empresa al Servicio del País. 1922-1972. Buenos Aires: Yacimientos Petrolíferos Fiscales.

Zanata, L. (2005). Auge y Declinación de la Tercera Posición. Bolivia, Perón y la Guerra Fría, 1943-1954. Desarrollo Económico, 45 (177), $25-53$ 
Zuleta, M.C. (2011). Los Primeros Años de YPFB y las Encrucijadas de la Industria Petrolera Boliviana en sus Orígenes, 1936-1945. Notas preliminares.RevistaH-industri@. Revista de Historia de la Industria, los servicios y las empresas en América Latina, 5 (8). Disponible en http:// www.hindustria.com.ar/images/client_gallery/HindustriaNro8Indice. htm_[01-06-2013].

\section{Archivos consultados}

Archivo de la Cancillería, Ministerio de Relaciones Exteriores, Comercio Internacional y Culto, Buenos Aires, Argentina.

Archivo de la Cancillería, Ministerio de Relaciones Exteriores, La Paz, Bolivia.

Benson Latin American Collection, University of Texas at Austin, Estados Unidos de América.

Biblioteca Tornquist, Banco Central de la República Argentina, Buenos Aires.

Centro de Pesquisa e Documentação de História Contemporânea do Brasil (CPDOC), Fundação Getulio Vargas, Rio de Janeiro, Brasil.

Foreign Relations of The United States. Argentina y Bolivia, 1937 a 1945.

Disponible en http://digicoll.library.wisc.edu/cgi-bin/FRUS/FRUS [01-07-2012].

\section{Periódicos}

La Calle, La Paz, 1941.

Recibido: 22-11-2012

Aceptación de la versión final: 10-04-2013 